\title{
Entrevista
}



Entrevista - Diálogos Midiológicos 28

\section{Um olhar sobre história, a televisão e a Comu- nicação na América Latina}

A look at history, television and Communication in Latin America

Una mirada a la historia, la televisión y la Comunicación en América Latina

Mirta Varella

Entrevista concedida a Camila Escudero*

M irta Varela nasceu em 1961, em Buenos Aires. Apesar de ter formação na área de Letras - defendeu a tese de doutorado intitulada "Cultura de masas, técnica y nación. La televisión argentina 1951-1969" na Faculdade de Filosofia e Letras da universidade de Buenos Aires -, vem atuando nos últimos anos com intensa produção e pesquisas na área da Comunicação Social. Atualmente, é pesquisadora do CONI-

CET (Conselho Nacional de Investigação Científica) e professora titular da cadeira de "Historia de los Medios de Comunicación"

" Doutoranda em Comunicação Social no curso de Pós-Graduação da Escola de Comunicação da Universidade Federal do Rio de Janeiro (UFRJ). Rio de Janeiro-RJ, Brasil. E-mail: camilaescudero@uol.com.br 
no Departamento de Ciências da Comunicação, da Faculdade de Ciências Sociais (UBA).

Entre seus principais livros publicados, destacam-se: "La televisión criolla. Desde sus inicios hasta la llegada del hombre a la Luna 1951-1969" (2005); "Audiencias, cultura y poder. Estudios sobre televisión" (1999); "Los hombres ilustres del Billiken. Héroes en los medios y en la escuela" (1994), entre outros. E acaba de publicar junto con Mariano Mestman, "Masas, pueblo, multitud en cine y televisión" (2013). Tem artigos traduzidos para o inglês, francês, alemão, português e italiano.

No início desta década, Mirta realizou pesquisas na Universidade de Paris VIII (2005) e foi professora visitante na Universidade de Berlim, na qual obteve bolsa da Fundação Alexander Von Humboldt (2008). Costuma trabalhar, entre outros temas, com a história dos Meios ancorada por conceitos teóricos da Sociologia da Cultura, apesar de pontuar que, a Sociologia da Cultura tem dado pouco espaço aos Meios, em particular a televisão, e tem se preocupado com as audiências ou com as midiatizações da sociedade, mas com poucos trabalhos sobre a programação, o que seria fundamental, especialmente num momento em que, nas palavras da pesquisadora argentina, se fala em "morte da televisão". "Creio que é bom falar que essa morte é no sentido de que hoje o meio hegemônico é a Internet e não mais a televisão, ainda que a televisão conserve um lugar central no sistema midiático”, diz. Neste sentido, ainda de acordo com Mirta, ver seriados como se fossem filmes, a qualquer horário, ou assistir a muitos capítulos seguidos, já não implica para a televisão, enquanto meio, um modo de ser produzida, uma linguagem, uma estética, mas também um modo de recepção, que foi completamente transformado. Isso repercute e tem consequências na maneira de como se produz televisão hoje.

Mirta Varela acredita que, na América Latina, a história dos Meios de Comunicação ainda está toda por ser escrita e que, a partir de intercâmbios na área da Comunicação entre os países, é possível "interiorizar" a ideia de que o continente é um bloco. "Claro que somos um bloco, mas isso precisa fazer sentido para nós, latino-americanos", defende. A exceção, do seu ponto de vista, seria o Brasil, país que, segundo Mirta, a impressiona pela capacidade 
de organização e institucionalização do campo comunicacional. Ao mesmo tempo, defende mais verbas para pesquisas na área da Comunicação na Argentina e percebe, o atual momento do país, como central. "Creio que nunca se havia visto na Argentina com tanta clareza a importância política dos Meios de Comunicação”.

Revista Intercom - Como se interessou em pesquisar a televisão e a história dos Meios?

Mirta Varela - Minha formação original é em Letras e no momento em que estava estudando Literatura me dei conta de que o que mais me interessava era a Sociologia da Literatura e da Cultura, ou seja, como pensar o papel da Literatura na sociedade. Passei a pensar então quais seriam as outras formas de cultura na sociedade e, em algum momento, percebi que, para mim, a Literatura deixou de ser o lugar central onde a sociedade trocava seus símbolos, suas expectativas e havia outras práticas que se tornavam mais relevantes, não do ponto de vista estético, mas do social e cultural. Comecei a olhar para outros lados, como para a música, para os jovens e o que eles faziam em termos de consumos culturais e também, em termos mais amplos, a indústria cultural. Meus primeiros trabalhos não foram só de televisão, foram sobre o rock, sobre uma revista impressa ("Billiken", da Editorial Atlántida), sobre a relação entre escola e Meios de Comunicação. E neste momento, me dei conta de que o meio televisivo, no início dos anos 1990, era o mais importante na Argentina e estava completamente desatendido. Nesta época, começavam a surgir os primeiros trabalhos específicos sobre televisão na Argentina mais não havia nenhuma história da televisão, salvo algumas histórias de jornalistas publicadas na imprensa, ou testemunhos de gente que havia trabalhado na televisão, mas nada além disso. Na verdade, isso foi um incentivo porque era um lugar vazio: não havia investigação, sobretudo do ponto de vista que me interessava, que era reconstruir como se havia chegado a formar uma cultura televisiva na Argentina. Dei-me conta de que seria necessário tentar reconstruir como se havia constituído uma cultura televisiva argentina pensando que não era exatamente o que havia ocorrido em outras sociedades, que não bastava traduzir o que ocorreu nos Estados Unidos ou na Europa, sendo que precisa- 
va entender o que tinha feito minha sociedade com a televisão. E que era importante ainda adotar uma perspectiva histórica frente a um meio que fazia da novidade seu principio constitutivo. Dessa maneira, se poderia ler a televisão por completo.

Revista Intercom - Qual a base teórica do seu trabalho?

Mirta - Acredito que Raymond Willians é uma referência fundamental porque ele foi um autor muito importante na Argentina para a formação dos primeiros trabalhos em Sociologia da Cultura. Beatriz Sarlo traduziu muita coisa de Raymond Willians e faz circular, também, uma entrevista dele em sua revista nos anos 1980. Raymond Willians tem uma circulação bastante peculiar no campo intelectual argentino. Serviu para enfrentar e debater o Estruturalismo e os estudos de Semiótica e do que havia sido, nos anos 1970, o peso dos estudos estruturalistas mais clássicos. Eu começo a estudar justamente no momento em que Williams começa a ter uma circulação muito importante. Por outro lado, tem Pierre Bourdieu, sem dúvida, acredito que são os dois pilares da Sociologia da Cultura que foram centrais para mim, num contexto onde Clifford Geertz, Carlo Ginzburg e Michel de Certeau também eram lidos com o objetivo principal de se encontrar argumentos para a interpretação de processos culturais que acabavam não sendo compreendidos completamente. E também tem os autores latino-americanos, que para mim foram muito importantes. Acredito que o livro "Dos Meios às mediações", de Jesús Martín-Barbero, e todos os debates que ele suscitou, é um marco fundamental na minha formação. Para mim, foi encontrar alguém que havia escrito algo magnífico sobre os temas que mais me interessavam e ver as reações intelectuais que suas intervenções produziam. E depois, creio que, ligado a isso, não sei se autores, mas uma quantidade enorme de discussão que tem a ver com Frankfurt, digamos especialmente com Benjamin, mas também com leituras menos sistemáticas de Leo Lowenthal e Siegfried Kracauer que para mim foram muito marcantes. E é claro a discussão proposta pelos Estudos Culturais britânicos. Principalmente nos anos iniciais da minha formação, li muito e avidamente os envolvidos com os Estudos Culturais britânicos. Na Argentina, acredito que tive a sorte de estar em contato 
com gente muito interessante, como Beatriz Sarlo e Carlos Altamirano e, no campo da Comunicação, com Jorge Rivera e Aníbal Ford com quem trabalhei muitos anos. Acredito que todos foram grandes formadores intelectuais na Argentina.

Revista Intercom - Poderia falar um pouco mais da opção pela linha da Sociologia da Cultura e não de outras disciplinas, como Semiótica, por exemplo.

Mirta - No campo da Comunicação, os Estudos Culturais trouxeram muitos conceitos e produziram um momento de grande debate e florescimento, mas houve em parte certo esgotamento de alguns caminhos e, sobretudo, o privilégio de uma abordagem etnográfica que resultou em apontamentos importantíssimos sobre as práticas e os sujeitos em relação à música, à dança, ao esporte, às culturas juvenis etc. Porém, ao mesmo tempo significou o deslocamento dos Meios do seu foco de atenção. É como se os Meios tivessem ficado como objetos da Semiótica e da Economia Política da Comunicação e a Teoria Cultural não tivesse mais nada a dizer sobre esse assunto. Tenho a impressão de que vale a pena rever sobre seus fundamentos porque nem a Semiótica, nem a Economia Política abordam alguns problemas irresolutos. A Semiótica reduz as condições de produção dos Meios a abstrações que, em muitos casos, nos fazem mais que ocultar determinações econômicas. Por outra parte, não deixa de resultar a suspeita de que uma teoria com pretensão científica sirva como principal ferramenta para os estudos de mercado. A Economia Política, por sua parte, reduz a linguagem e a estética a sua condição instrumental e a trata como mero "conteúdo" que pode ser transmitido ou veiculado e ao qual, desta forma, se nega toda a especificidade. Parece-me que, nesse sentido, é um momento importantíssimo para a retomada dos estudos sobre os Meios do ponto de vista da Sociologia da Cultura que tem muito a dizer sobre os Meios e não somente sobre as mediações.

Revista Intercom - Quais as principais tendências de pesquisa sobre TV na atualidade?

Mirta - Acho que há muitas linhas de trabalho. Uma delas é como a televisão 'representa' alguns temas. Como a televisão representa 
os jovens, os episódios históricos, os acontecimentos políticos, os sujeitos sociais etc. Reside aí a ideia de que, assim como poderíamos ler a sociedade na Literatura ou no Cinema, a televisão também poderia ser um lugar apropriado para isso. Ao mesmo tempo, apesar de muito importante, tem como problema, na minha opinião, não se destinar a encontrar as especificidades televisivas. Mas é uma linha de trabalho que cada vez tem mais importância, sobretudo nos lugares onde os arquivos de televisão se mostram mais acessíveis. Outra linha que continua sendo relevante é o estudo dos gêneros, com alguns gêneros se destacando - na América Latina, se destaca claramente a telenovela. Ela acaba por abarcar a atenção da investigação, especificamente, a telenovela latino-americana, mas hoje também, pode abarcar os seriados norte-americanos. Há toda uma linha de trabalho neste sentido que em muitos casos parte da ideia ou do objetivo de legitimar a produção televisiva. Inclusive, muitas revistas de Cinema têm lançado números especiais sobre seriados de televisão. É como se, finalmente, houvesse chegado uma 'televisão de qualidade', legítima. Pessoalmente, me parece que falam um pouco da 'morte da televisão'. Supõe-se a ideia de que a televisão deixa de ser um objeto de interesse central para o público e passa a ser um objeto de interesse para os críticos. Não digo os investigadores, digo os críticos. Falo no sentido de que os críticos de Cinema têm tratado o Cinema quase sempre tentando alavancar, resgatar e construir um campo. Teve início nos últimos anos um trabalho de construção do campo nacional televisivo. Isso é algo novo, a televisão sempre foi um meio abastado, muito pouco reconhecido e, portanto, não seria um campo de reconhecimento legítimo. Eu acredito que o trabalho que tem feito no Brasil Arlindo Machado a respeito da televisão supõe a construção de um campo da televisão brasileira, quais são os melhores programas da história da televisão, que valem a pena estar na história da televisão etc. Isso eu creio que é muito importante para revisar, digamos, essa história da televisão e também para atualizá-la, mas também coloca a televisão como objeto de uma crítica estética que até um tempo não existia. Mas voltando à 'morte da televisão', creio que é bom falar que é no sentido de que hoje o meio hegemônico é a Internet e não mais a televisão, ainda que a televisão conserve 
um lugar central no sistema midiático. Esse deslocamento e sua hegemonia implica que a televisão pode ser reconhecida pela crítica porque em algum ponto se mostra menos perigosa que como era. Outra linha de trabalho tem a ver com Economia Política. São pesquisas que têm uma visão quase oposta, ou seja, uma visão que em algum momento pode ser de denúncia de relações econômicas das empresas, como as empresas midiáticas se estruturam, que lugar ocupa a televisão nesse cenário. Esta é uma área que teve um auge nos últimos anos na Argentina, particularmente, mas creio que também em toda América Latina. Penso que parte da ideia de que a propriedade da televisão ou a propriedade dos Meios deixam marcas, pegadas na tela televisiva, que mudando a propriedade dos Meios, pode-se abrir caminho para mudança na programação, na estética, na linguagem. De alguma maneira, não dá relevância à questão da linguagem televisiva. Neste sentido, creio que a Sociologia da Cultura tem dado pouco espaço aos Meios e em particular a televisão. Tem se preocupado com as audiências ou com as midiatizações da sociedade, porém, tem havido poucos trabalhos sobre a programação. Há, claro, estudos interessantes sobre o que ocorre efetivamente na televisão como instituição, como instituição midiática, como instituição social e como instituição cultural. No Brasil, existem mais, mas na Argentina, há ainda poucos trabalhos sobre o funcionamento institucional da televisão. Não conhecemos bem ainda a formação profissional das pessoas que trabalham na televisão e quais são as instituições que formam essas pessoas. Como tem se dado esse processo historicamente? De onde vem e como são construídos os corpos profissionais da televisão? Isso, na Argentina, ainda é completamente desconhecido e em poucos países se tem trabalhado como tem sido constituído o campo televisivo. Ou a pergunta é: existe um campo televisivo?

Revista Intercom - Já que tocou no assunto da Internet, poderia falar um pouco de como você vê hoje a convergência de midias? A televisão indo para o celular, para o computador...

Mirta - O fundamental é que não se pode pensar mais a televisão como um meio de lugar. Hoje, a televisão é parte de outro emaranhado midiático que é a Internet. Isto não significa que 
não vamos mais ter televisão em casa e ver televisão, mas cada vez mais ocorre ver televisão de outros modos, pela Internet. Isso era ficção até pouco tempo e teve uma mudança impressionante. Ver seriados como se fossem filmes, a qualquer horário, ou assistir a muitos capítulos seguidos. Acredito que, nesse sentido, a televisão já não implica enquanto meio um modo de ser produzida, uma linguagem, uma estética, mas também um modo de recepção, que foi completamente transformado. Isso repercute e tem como consequência sobre como se produz televisão hoje. Assim, entramos não só na questão da mobilidade, mas do fluxo televisivo, dizer que esse fluxo pode ser transformado. Se alguém quer ver programas pela Internet pode não seguir a ordem de que um único canal de televisão o produz sozinho. Isso traz muitas consequências. Há uma coisa que me pergunto do ponto de vista da história dos Meios: não está se levando em conta a história dos Meios para se entender o momento atual. E isso é útil, assim como lembrar que a televisão foi o primeiro Meio a usar a tela, essa fonte luminosa, que ainda está hoje num lugar central, apesar das mudanças. A tela está no seu momento de maior auge. Creio que é preciso entender o que significou essa construção da tela da televisão como centro da vida social. É uma história que valeria a pena ter mais clara. Por outro lado, acredito que a história também serve para entender o que está ocorrendo na recepção da televisão pela Internet e como que se transformaram os gêneros com a imprensa gráfica no século 19. Para mim, há uma analogia necessária entre como o folhetim se fixou no século 19 como o primeiro gênero de ficção da imprensa gráfica e no momento em que deixou de circular na imprensa, e passou a ser consumido como livro, como novela. Essa passagem da imprensa gráfica, dos diários, dos jornais à novela foi um processo de legitimação cultural e de transformação de gênero, do modo de recepção, e de transformação de público. Isso é o que está ocorrendo com os seriados, e com muitas telenovelas da atualidade. Essa passagem da televisão para a Internet é uma transformação de público. Um público que há 15 anos nunca havia visto um seriado de TV hoje o consome avidamente. Aceita este consumo como natural. Tem a ver com o modo de recepção que é distinto. Já não tem que esperar a exibição em série, não depende da televisão, se sente mais 
ativo porque baixa o programa de Internet, ou tem o DVD - ou até pouco tempo atrás comprava o DVD... Há pouquíssimos trabalhos pensando sobre as hipóteses da Sociologia da Cultura, o que seria muito útil incentivar essa zona de investigação.

Revista Intercom - Como está o campo da Comunicação na Argentina hoje? Os cursos de pós-graduação, as pesquisas? O que está se pensando? Mirta - Estamos num momento onde os Meios ocupam um lugar central na Argentina. Creio que nunca se havia visto no país com tanta clareza a importância política dos Meios de Comunicação. Todos sabíamos, e muitos vinham repetindo, há muito tempo, porém, nunca teve tanta evidência a importância política como nos últimos anos. O debate sobre a Lei de Comunicação Audiovisual nos mostrou a necessidade de se conhecer mais sobre o funcionamento e sobre as pesquisas sobre os Meios. Neste sentido, há um reconhecimento do campo e uma etapa mais madura de reflexão sobre a Comunicação. Vemos muitos pesquisadores e intelectuais participando nos Meios sobre o debate dos Meios na Argentina. Por outro lado, temos a formação de comunicadores e investigação em Comunicação. Creio que é um panorama complexo. Há uma enorme quantidade de carreiras de Comunicação, de mestrados, de doutorados... É um momento em que parece agora estar estabilizado, mas houve um período de explosão, que fez muitas universidades, principalmente as grandes, reduzirem o número de matrículas de seus cursos. A carreira na área de Comunicação de Buenos Aires chegou a ser mais numerosa que muitas carreiras tradicionais. Mas, neste momento, creio que isso está mais estabilizado e em níveis racionais (risos). E há mais diversidade. Estão aparecendo a todo tempo trabalhos e estudos mais variados e específicos sobre temas de Comunicação. Antes, havia uma linha de Comunicação e Cultura, agora na mesma universidade pode haver quatro ou cinco linhas com temas mais específicos. Isto por um lado é bom, porque essa diversidade dá conta de uma complexidade de um campo que vem ganhando seus próprios debates. Por outro lado, vem ocorrendo na Argentina a falta de reconhecimento da área da Comunicação em muitas instâncias, principalmente no financiamento de pesquisas. Eu pertenço, por exemplo, ao CONICET - Conselho Nacional 
de Investigações Científicas e Técnicas e nele não tem uma área de Comunicação, ou seja, a Comunicação está dentro da área da Sociologia. Isso, às vezes, torna muito difícil a avaliação de projetos, financiamentos, uma difícil inserção para muitos pesquisadores. Esse, acredito, é o maior problema.

Revista Intercom - Qual a percepção que você tem do campo da Comunicação no Brasil e na América Latina, de uma maneira, em geral? Mirta - No Brasil sempre me deslumbra a capacidade de organização e institucionalização do campo da Comunicação. Creio que existe um campo que está institucionalizado, com congressos enormes, sistematizados, uma quantidade grande de publicações. É muito impressionante. Claro que a institucionalização pode ser uma arma de mão dupla, mas creio que isso supõe uma política de quantidade. Há muita gente nas universidades participando desse campo, dos congressos, das publicações, dos cursos de pós-graduações, mas ao mesmo tempo isso tem dado como resultado investigações de enorme qualidade. Não estou dizendo que todas são, porém, isso proporciona algumas investigações que realmente são inovadoras e de alto nível. E quando digo isso, digo com admiração, com muito respeito pelo modo como o Brasil vem trabalhando e se destacando no campo. Porque me parece que conseguiu combinar algo que não é fácil, que é a quantidade, com muitos pesquisadores, professores, estudantes, com a qualidade, com pesquisas profundas, importantes, reveladoras. Sobre o resto da América Latina, obviamente não conheço tudo de toda parte, porém, creio que é uma área que teve dois momentos realmente importantes: um deles remete aos anos 1970, com a Teoria da Dependência aplicada ao imperialismo cultural. Neste momento, os Meios de Comunicação ganharam um espaço central, ou seja, a América Latina viu que o imperialismo cultural se conseguia, sobretudo, através dos Meios. Outro remete aos anos 1980 e 1990, quando ganhou importância o campo da Comunicação e Cultura, que também colocou os Meios de Comunicação num lugar central. Hoje, acredito que, neste momento, do ponto de vista político, a centralidade dos Meios e sua legitimidade em muitos países do nosso continente para mim é um terceiro momento, que deveria 
ser aproveitado por todos nós, para repensar e ver o quanto temos em comum e estamos juntos. Penso que isso tem a ver com o fato de quanto mais se faz intercâmbios, em geral, se tende a aprofundar a ideia de uma América Latina como um bloco, que na verdade é uma ideia externa, que não pertence a nós, latino-americanos. Claro que somos um bloco, mas isso precisa fazer sentido para nós. Aí entram os trabalhos comparativos, reais e precisos sobre como vem se ocorrendo as coisas. Nesse sentido, me parece, que a história dos Meios ainda não está escrita na América Latina. É uma história que precisa ser trabalhada, contada, que pode reconstruir quantas trajetórias em níveis de um país ou outro, quantas personagens dos Meios já circularam, quantas empresas já existiram... A história da televisão tem muitas histórias. A General Eletric exportando experimentos dos EUA para muitos países da América Latina foi uma constante nos anos 1940-50. As histórias se repetem, porém, não as conhecemos. Parece que falta muito trabalho e não pensar que somos latino-americanos distantes uns dos outros, mas ver de que maneira nossas histórias estão entrelaçadas. Nesse sentido, creio que mais trabalhos sobre a história dos Meios podem ser úteis e interessantes. E também encontros, que implicam conhecer mais, poder trabalhar em comum, ter um objeto de investigação em comum e produzir mais trabalhos reais e de aplicação prática.

Revista Intercom - Poderia falar um pouco do seu trabalho no CO. NICET?

Mirta - O CONICET é o que é mais parecido no Brasil com o CNPQ. É um Conselho de pesquisa que financia pesquisadores, reúne esses investigadores, tem bolsistas de mestrado, de doutorado. E tem alguns centros de investigação também. No meu caso, meu centro é a Universidade de Buenos Aires, na Faculdade de Ciências Sociais. Meu trabalho tem a ver com apresentar um projeto de investigação que nos últimos anos teve duas linhas: uma é essa da história da mídia. De estabelecer um projeto reflexivo de como se faz história da mídia e dos Meios na América Latina e esse teve como primeiro resultado a ReHime, uma rede de história dos Meios [significado da sigla em espanhol: Red de Historia de los Medios] que formamos, temos um site com várias publicações, 
documentos etc. [http://www.rehime.com.ar]. Existe há cerca de quatro anos. A ideia do projeto consiste justamente em estabelecer uma rede de pesquisadores sobre a história dos Meios na América Latina e tentar fomentar encontros, projetos e intercâmbios tentando pensar modos de escrever a história dos Meios na América Latina que de alguma maneira são mais adequados para a nossa história, como referências teóricas. Muitos autores da Europa ou Estados Unidos não nos servem completamente e isso implica repensar e incentivar muitas produções e áreas. Inclusive há alguns países da América Latina que sequer ainda consideram a história dos Meios. Esta é uma parte do trabalho que ocupa bastante do meu tempo nos últimos anos. Além disso, sou titular da cadeira de história dos Meios da Universidade de Buenos Aires. Então, este projeto envolve outros professores da Universidade, estudantes, pesquisadores. E o outro projeto, que existe desde 2008, tem a ver com a representação das massas no Cinema e na televisão. Esta ideia de pensar o conceito de massas que se trava na Comunicação e que durante muito tempo foi descrito como Meios de Comunicação de Massa, justamente. Meu projeto tem a ver com como os Meios audiovisuais, o Cinema e a televisão, também mostraram imagens dessas massas. Não só as construíram como público, sendo que também as mostraram como cena, construíram imagens acerca delas. Então o projeto, que também é em grupo, é revisar como acontecimentos políticos na Argentina e também de outros lugares foram representados e construídos por meio das imagens. Entendemos que têm ocorrido muitos debates sobre questões conceituais. A história intelectual tem escrito muito sobre o que significa e de que maneira tem sido construído o conceito de massa, povo, multidão. Porém, há poucos estudos sobre como as imagens construíram essa massa, esse povo, essa multidão. Bem, e a hipótese é de que as imagens não são meramente tradução de conceitos audiovisuais, no entanto, dizem mais coisas, que a realidade os conceitos não dizem. 